\title{
A Study on Effective Instructional Design for IoT Security Education Focusing on Experiential Learning
}

\author{
Kosuke Kaneko *, Yoshitatsu Ban ${ }^{\dagger}$, Koji Okamura *
}

\begin{abstract}
This paper discusses about effective instructional design for fostering security engineers, especially focusing on experiential learning. The authors prepared two groups, the proposed experiential learning group (experimental group) and non-experiential learning group (control group), and investigated each learning effectiveness by using several evaluation metrics. The evaluation metrics included pre-/post-test scores, delayed-test score and learning motivation score. The result of statistical evaluation was that there was no significant difference about pre-/post-test scores and also learning motivation scores between the two group. However, there was significant difference about delayed-test scores between them. This interesting result explains that the learners in the both groups had higher learning motivation and they actually acquired knowledge about cybersecurity in each lecture, nevertheless, almost learners in the non-experiential learning group couldn't keep to retain the knowledge they acquired several weeks ago, meanwhile almost learners in the experimental learning group could keep it. This result indicates that experiential learning can influence learner's knowledge retention and has possibility to bring long-term knowledge retention than the case of non-experiential learning. Although the fact was empirically known among most lecturers, this experiment proved it based on statistical quantitative evidence. The contribution of this paper is the quantitative evidence. The result of this paper provides one of the evidences that instructional design including experiential learning brings superior learning effectiveness for cybersecurity education.
\end{abstract}

Keywords: Cybersecurity Education, Experiential Learning, Instructional Design

\section{Introduction}

With total number of cyberattacks is increasing year by year, human resource development of cybersecurity engineers, who protect computer systems from these cyberattacks, becomes an urgent task all over the world. The demand of the human resources is in excess of the supply and shortage of them is happened. Japanese Ministry of Economy, Trade and Industry published a report that approximately 200 thousand of security engineers will become shortage at Tokyo

\footnotetext{
* Cybersecurity Center in Kyushu University, Fukuoka, Japan

${ }^{\dagger}$ Human Techno System Co., Ltd., Fukuoka, Japan
} 
Olympic Games 2020 [1]. In addition to the situation, huge number of various types of computers including IoT (Internet of Things) devices appear into our lifestyle environment and cyberattacks aiming to the devices are increasing. Another report published by Japanese Ministry of Internal Affairs and Communications mentioned that total number of IoT devices becomes over 30 billion by 2020 [2]. The demand of human resources of the security engineers will be more exceed at that time. In response to these background, every engineer, not only cybersecurity specialists but also general engineers who are related to IoT services, will need to learn knowledge about cybersecurity as basic knowledge of engineering. Consequently, cybersecurity education will be more required.

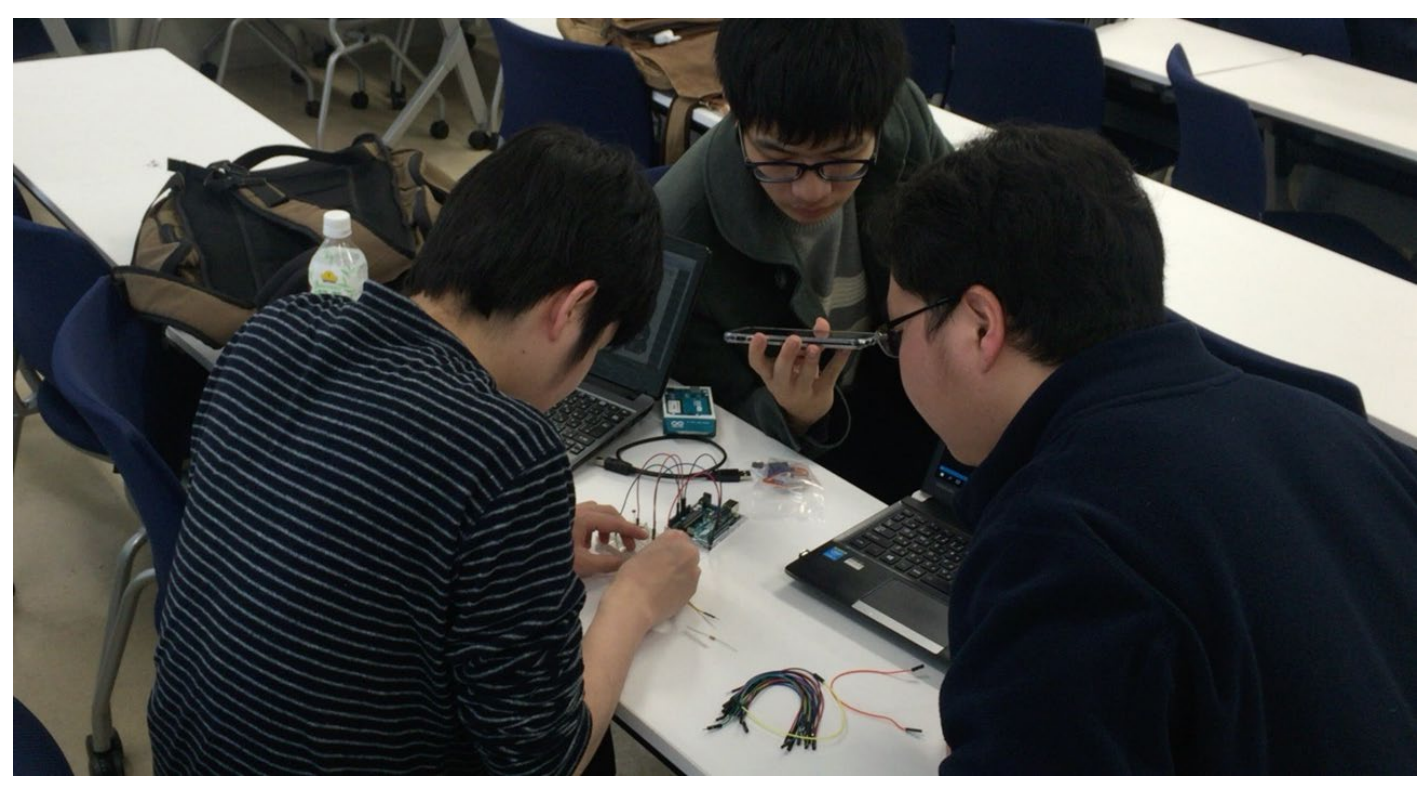

Figure 1: Appearance of the proposed experiential learning.

To provide effective education, lectures need to design superior instruction. One of the ideas achieving for the instruction is to take a practical experimental learning. Almost lecturers who teach about cybersecurity knowledge or skills empirically know that practical training or trill are surely effective for cybersecurity education. However, we haven't seen any quantitative evidence based on statistical results. Therefore, the purpose of this research is to investigate the learning effectiveness of experiential learning for fostering security engineers and also to find effective instructional design according to the results. Although there are various viewpoints to evaluate learning effectiveness, this research focused the four metrics; pre-/post-test score, delayed-test score and learning motivation score. The pre-/post-test score are one of metrics to indicate the degree of understanding learners acquired within a certain lesson. The delayed-test score is a metric to indicate the degree of knowledge retention after the lesson. The learning motivation score is a metric to indicate the degree of motivation to the lesson. The degree of understanding is a meaningful factor because it is one of direct metrics to judge whether the instructional design is superior or not. The degree of knowledge retention is also a meaningful because the retained knowledge leads to accumulate another knowledge they will learn. Also, loss of the knowledge makes the lecture nonsensical. Learning motivation are also meaningful factors because it leads an attitude for learner to actively study. 
This research adopted a learning course "Security Engineering Exercise" held in Kyushu University as an example of the experiential learning [3]. Figure 1 shows an appearance of the lecture scene in this course. They were trying to experientially develop an IoT product in consideration of security aspects. In this course, they acquired knowledge and skills for cyberdefense by learning the mechanism of cyberattacks. Therefore, they actually tried to execute several cyberattacks to IoT systems we prepared as an educational material and also tried to implement several protections into the vulnerable system to avoid these cyberattacks. This course was designed based on ADDIE (Analysis, Design, Development, Implementation, Evaluation) model. As another compared example of non-experiential learning course, in this research, we prepared a video-based e-learning course without any practical exercise. The contents of videobased educational material were the same one of the experiential learning course. By comparing the pre-post test score, delayed-test score and learning motivation score of each learner between the two learning groups, this research provides a result of learning effectiveness focusing on experiential learning.

This paper is composed of the following contents. The next section introduces instructional design of this course according to ADDIE model. Section 3 explains experimental procedure about the comparative experiment. Section 4 shows results of test scores of each learner between two groups. We discuss about the results and consider better instructional design in Section 5. Lastly, this paper concludes this research and explores potential area for future research.

\section{Instructional Design}

Knowledge retention is one of important factors in learning process. Knowledge is accumulated on the previous knowledge. Therefore, it is important to design instruction in considering with methods for keeping knowledge retention. As a basic model for the design, this research adopted a Learning Pyramid theory [4]. Figure 2 is a diagram describing the theory. The diagram is showing percentage of knowledge retention rate according to each teaching method. Passive teaching method such as just doing lecture (5\%), reading something $(10 \%)$, show something audio visual (20\%) or demonstrations (30\%) are not effective so much for keeping knowledge retention. On the other hand, participatory teaching methods such as group discussion (50\%), practical exercises $(75 \%)$ and teach something to other learner $(90 \%)$ are effective for keeping knowledge retention. In short, this theory indicates that a learner can acquire higher knowledge retention rate by applied participatory teaching methods than passive teaching methods. Therefore, we adopted participatory teaching methods into the proposed instructional design. Also, we designed the instruction in consideration with ADDIE model. The following subsections explain the details of ADDIE. 


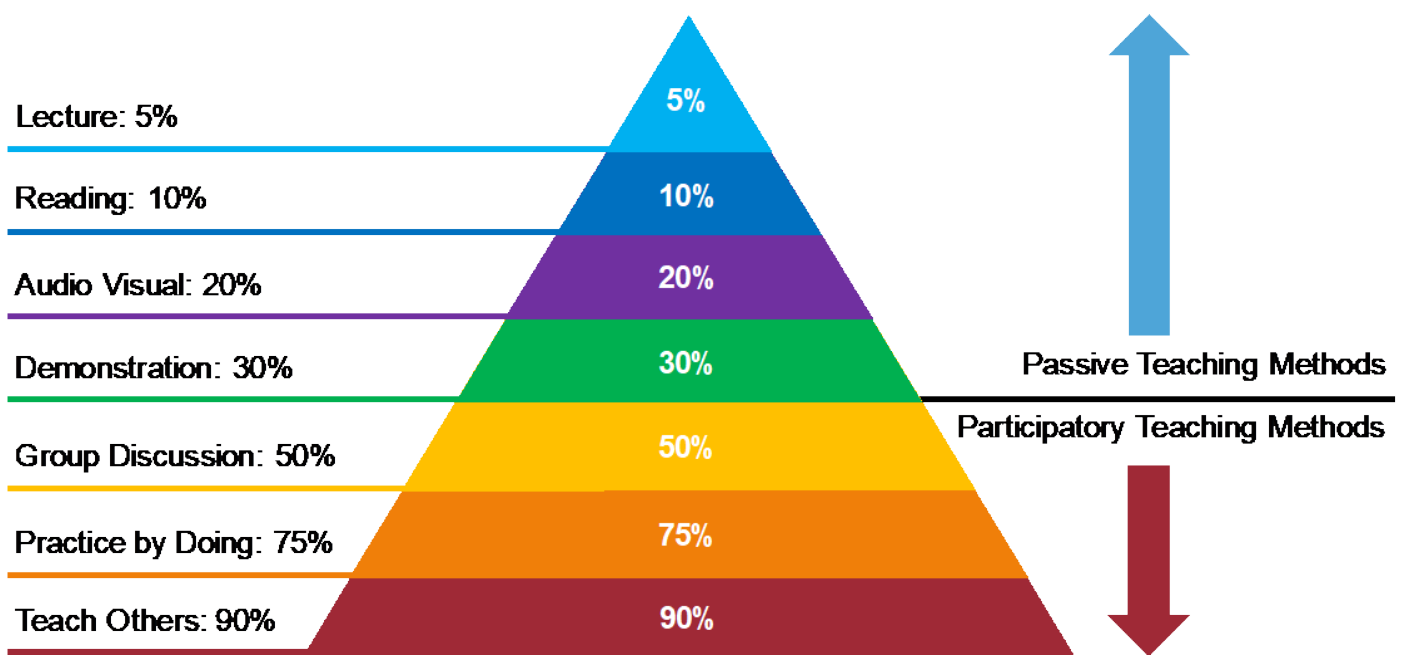

Figure 2: Diagram of Learning Pyramid Theory

\subsection{Analysis in ADDIE model}

In analysis part in ADDIE model, we discussed about the research subjects and made a persona model of them. The subject was a person who is interested in software/hardware development but don't know knowledge and skills about cybersecurity. I also selected the first-year flesh man as the subject. As teaching side, we only have one lecturer and one teaching assistant. Since the course is focusing on doing practical exercises, we had to restrict the total number of learners and designed better contents according to the total number. In this research, we set the limitation number is 10 persons.

\subsection{Design in ADDIE model}

In design part in ADDIE model, we firstly designed the curriculum of this course. This course had 15 lessons and each lecture had $90 \mathrm{~min}$. IoT security is too wide range fields such as frontend, backend, networking, gateway, hardware device, etc. to teach knowledge within the 15 lessons. We picked up currently popular topics of cyber security. Table 1 shows the curriculum. Each lesson had several practices that the leaners actually experienced cyber-attacks and cyber-defenses. For example, in the lesson of input device, they made an electric circuit by using a breadboard. Then, leaners tried to do cyberattacks to the system they made. Lastly, they repair the system without vulnerability. The details of the educational materials are explained in next subsection. 
Table 1: Curriculum of the proposed experiential learning

\begin{tabular}{|c|c|c|}
\hline No. & Topics & Contents \\
\hline 1 & About IoT & Generic architecture of IoT services \\
\hline 2 & Sever Side Engineering & $\begin{array}{c}\text { Generic architecture of web application, } \\
\text { Linux command, }\end{array}$ \\
\hline 3 & Account Hacking & $\begin{array}{l}\text { Brute-force attack, Dictionary attack, } \\
\text { Two-factor authentication }\end{array}$ \\
\hline 4 & Encryption and Anonymize & $\begin{array}{c}\text { Symmetric-key cryptography, } \\
\text { Public key cryptography, hash, k-anonymity }\end{array}$ \\
\hline 5 & SQL Injection & Database, SQL injection \\
\hline 6 & Access Point Hacking & Air-cracking, MITM attack, ARP spoofing \\
\hline 7 & Hardware Engineering & Generic electric circuit design \\
\hline 8 & Input Device & Electric circuit design for sensors \\
\hline 9 & Output Device & Electric circuit design for motors \\
\hline 10 & Bluetooth Module & Electric circuit design with Bluetooth module \\
\hline 11 & Delayed-test & Delayed-test \\
\hline 12 & Security by Design & Group work for final product \\
\hline 13 & Security by Design & Group work for final product \\
\hline 14 & Security by Design & Group work for final product \\
\hline 15 & Presentation & Presentation for final product \\
\hline
\end{tabular}

\subsection{Development in ADDIE model}

We developed several educational materials based on the instructional design. The materials contain several concepts to facilitate learning motivation based on ARCS model. ARCS model is a learning motivation model focusing on the four elements; Attention, Relevance, Confidence and Satisfaction [5]. Table 2 shows elements of ARCS of the proposed educational materials. The details of the educational materials are explained in next subsection. 
Table2: ARCS elements of the proposed educational material

\begin{tabular}{|l|l|}
\hline ARCS elements & Contents \\
\hline Attention & $\begin{array}{l}\text { Demonstration of cyber-attacks } \\
\text { Experiential educational materials }\end{array}$ \\
\hline $\mathbf{R}_{\text {elevance }}$ & Concrete scenarios for each lesson \\
\hline $\mathbf{C}_{\text {onfidence }}$ & Repair systems with vulnerability by themselves \\
\hline $\mathbf{S}_{\text {atisfaction }}$ & Post-tests after each lesson for checking their learning retention \\
\hline
\end{tabular}

We developed the educational material by using Raspberry Pi and Arduino. Figure 3 shows examples of the proposed educational materials we developed. The upper picture in Figure 3 is an educational material that a learner can experience cyberattacks of unauthorized access. The lower picture in Figure 3 is another educational material that a learner can experience cyberattacks to hardware devices.
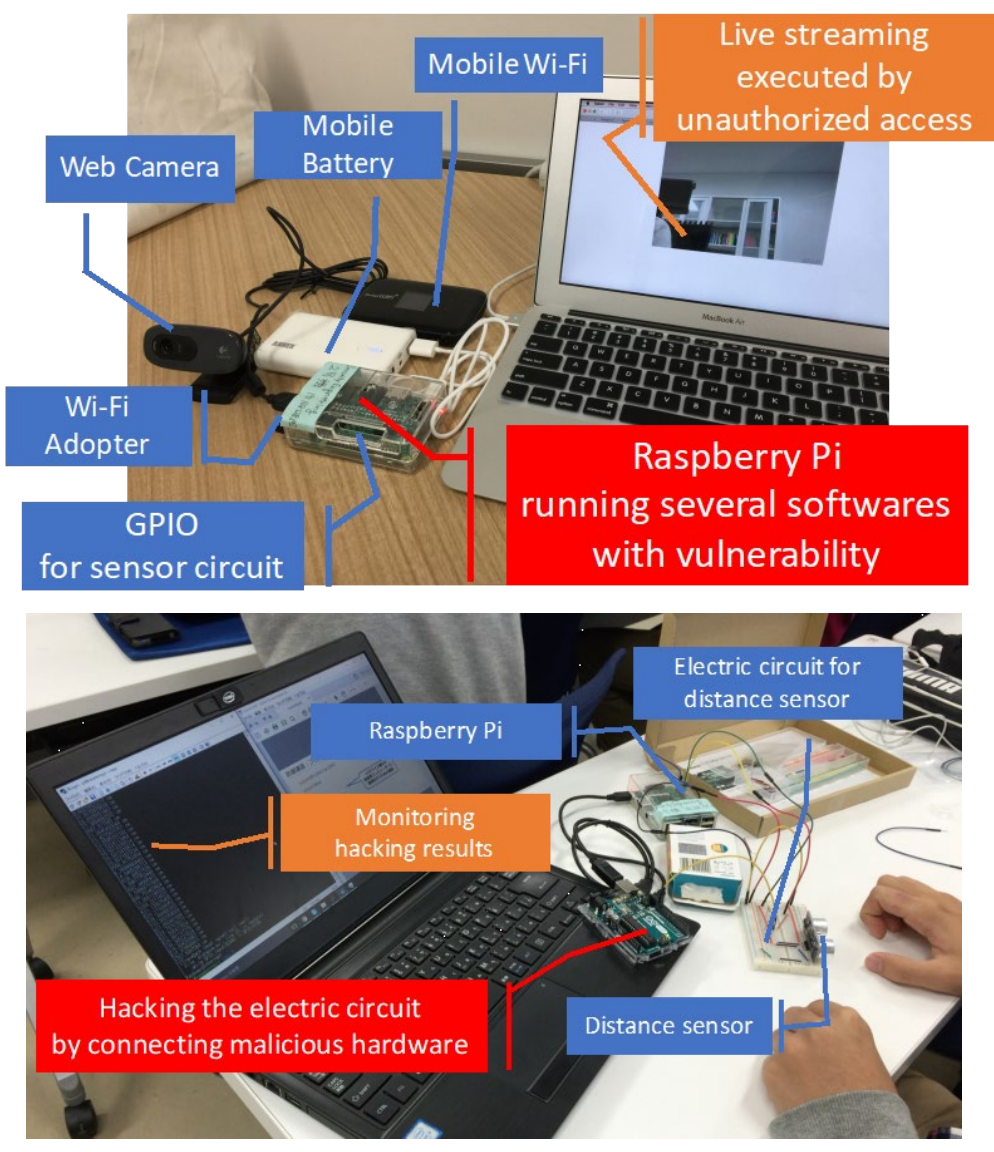

Figure 3: Educational materials for the proposed experiential learning course 


\subsection{Implementation in ADDIE model}

We practiced each lesson based on the instructional design by using the educational materials. Figure 4 shows appearances of this experiential learning. The learners made groups consisting of 2 or 3 members as showing the colored circles in the upper picture in Figure 4. They learned knowledge and skills for cyber-defenses by learning the mechanism of cyberattacks. They practically experienced the method of cyberattacks and cyber-defense through the practical exercises. The lower picture of Figure 4 shows an appearance a learner teaches something to another member in the group. These implementations of instructional design were based on the participatory teaching method in Learning Pyramid theory.
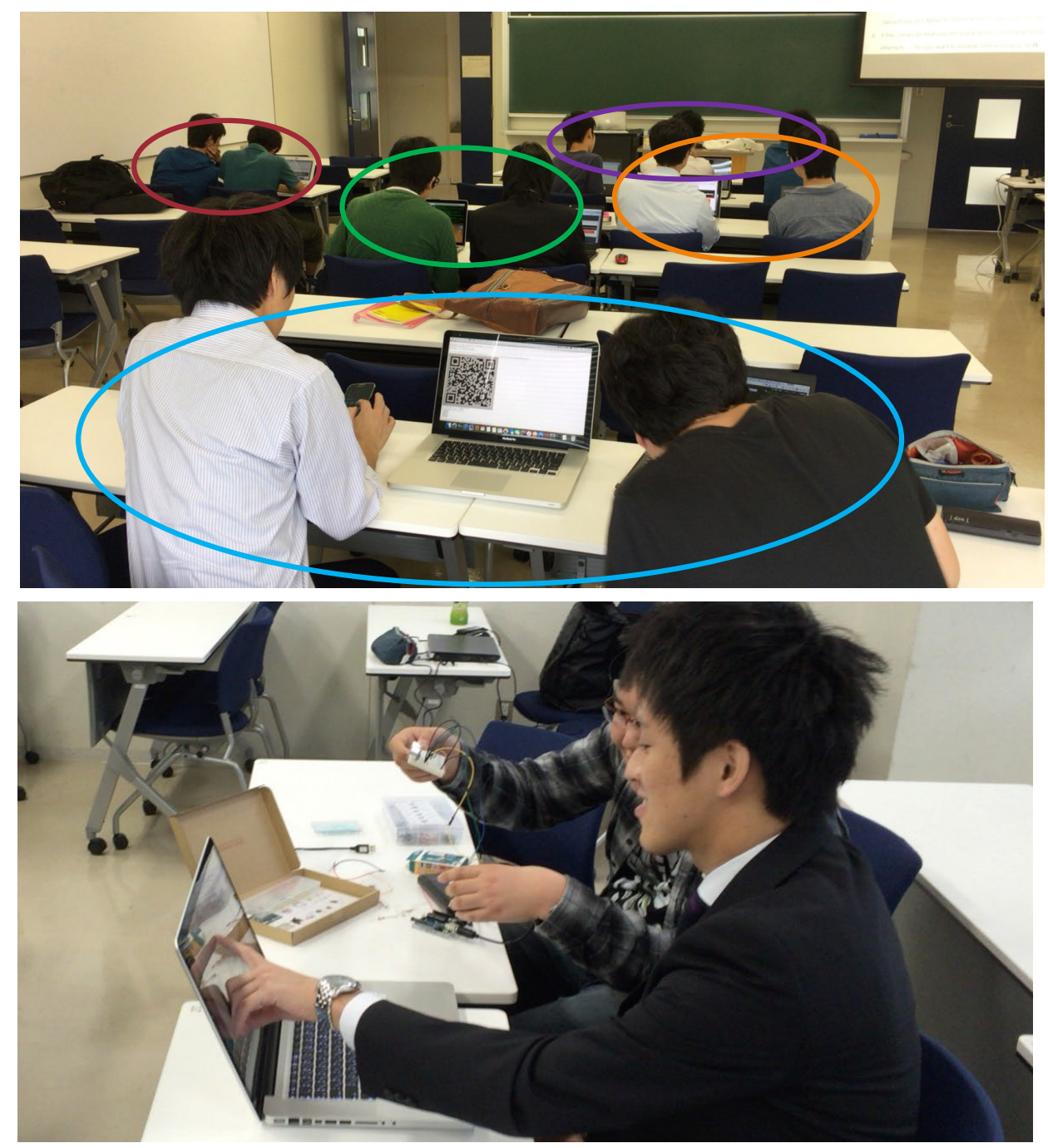

Figure 4: Appearances of group work scene of the proposed experiential learning course 


\subsection{Evaluation in ADDIE model}

We evaluated the learning effectiveness of this proposed instructional design from the three viewpoints; degree of understanding, degree of knowledge retention and degree of learning motivation. The degree of understanding was evaluated from the results of the pre-/post-test scores. The degree of knowledge retention was evaluated from the results of the delayed-test. The degree of learning motivation was evaluated from the results of questionnaire based on Instructional Materials Motivation Survey (IMMS) that measure the validity of the learning material construction based on ARCS model. The delayed-test was executed about one month later after they learned. The procedure and method for the evaluation is explained in the next section.

\section{Comparative Experiment}

We prepared non-experiential learning course as the control group for comparing learning effectiveness. The learning course was held very limited situation where didn't satisfy any condition of the participatory teaching methods of the Learning Pyramid theory. The details are explained in the next subsection. Every learner of the two group took pre-tests, post-tests and delayed-test. Figure5 shows overview of this comparative experiment.

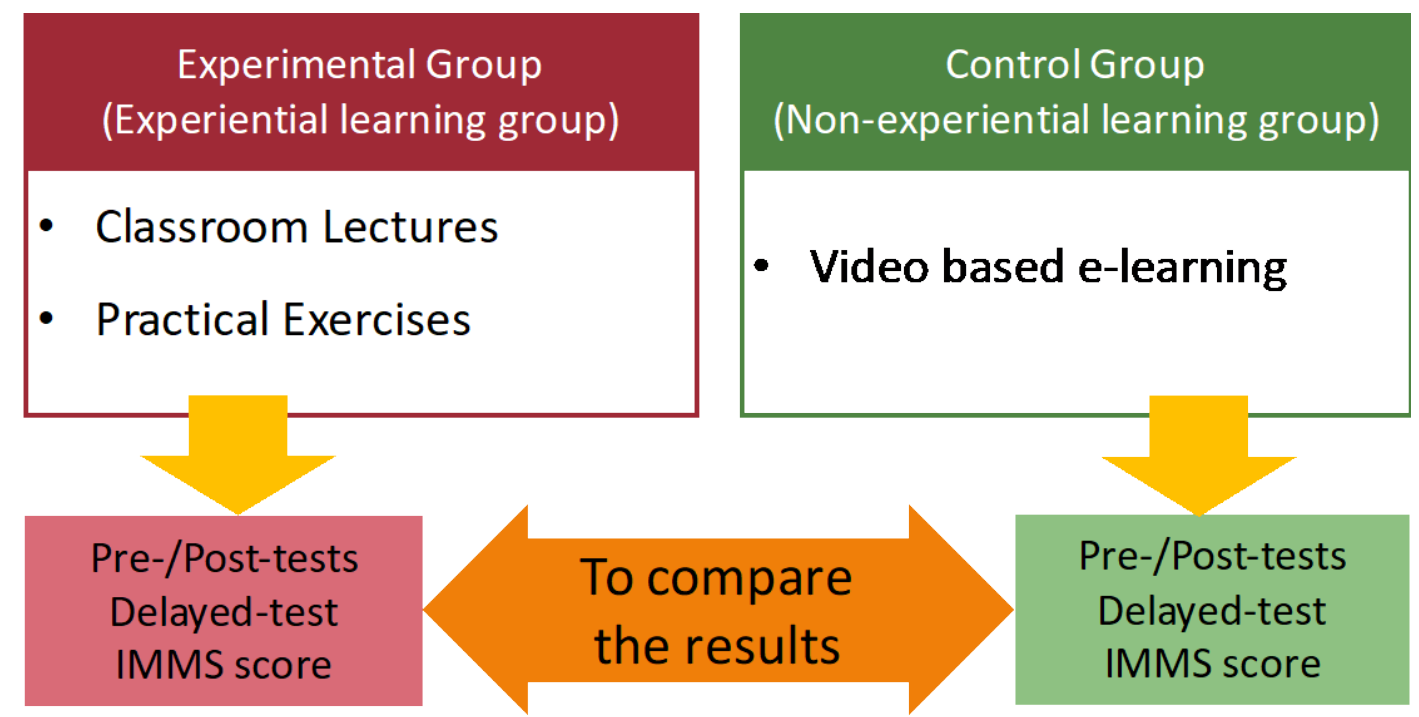

Figure 5: Overview of the comparative experiment.

\subsection{Instructional design of non-experiential learning}

Non-experiential Learning took video-based e-learning style. The contents of the learning topics were the same one of the experiential learning. The video content was developed from the same power point slides used in the classroom lecture of the experiential learning. The video content contained the topics of No. $3 \sim 10$ except from No. 7 in the curriculum list in Table 1. These seven 
topics were separated as a chapter in the video. In addition to that, in this non-experiential learning case, the exercise pages in these slides were removed. The video material explained the contents by woman's machine voice who read text messages in notes of each slide page. Amount of play time of the video e-learning course was about $30 \mathrm{~min}$. Different from the experiential learning, each learner prohibited to help each other. They just only watched the video with their own earphone. Figure 6. is appearance of the non-experiential learning course. In the course, learners gathered in one room and took the video-based e-learning course. The upper picture of Figure 6 is appearance of the learning scene. All learner had their own earphone and they focused to learn the contents. They were prohibited to communicate the other members even in the case that a learner is near to another learner like the lower picture of Figure6. The learning conditions, namely non-discussion, non-practical doing and non-teach to others, are very contrastive situation to the experiential learning course. These conditions were not satisfied with any participatory teaching method of the Learning Pyramid theory.
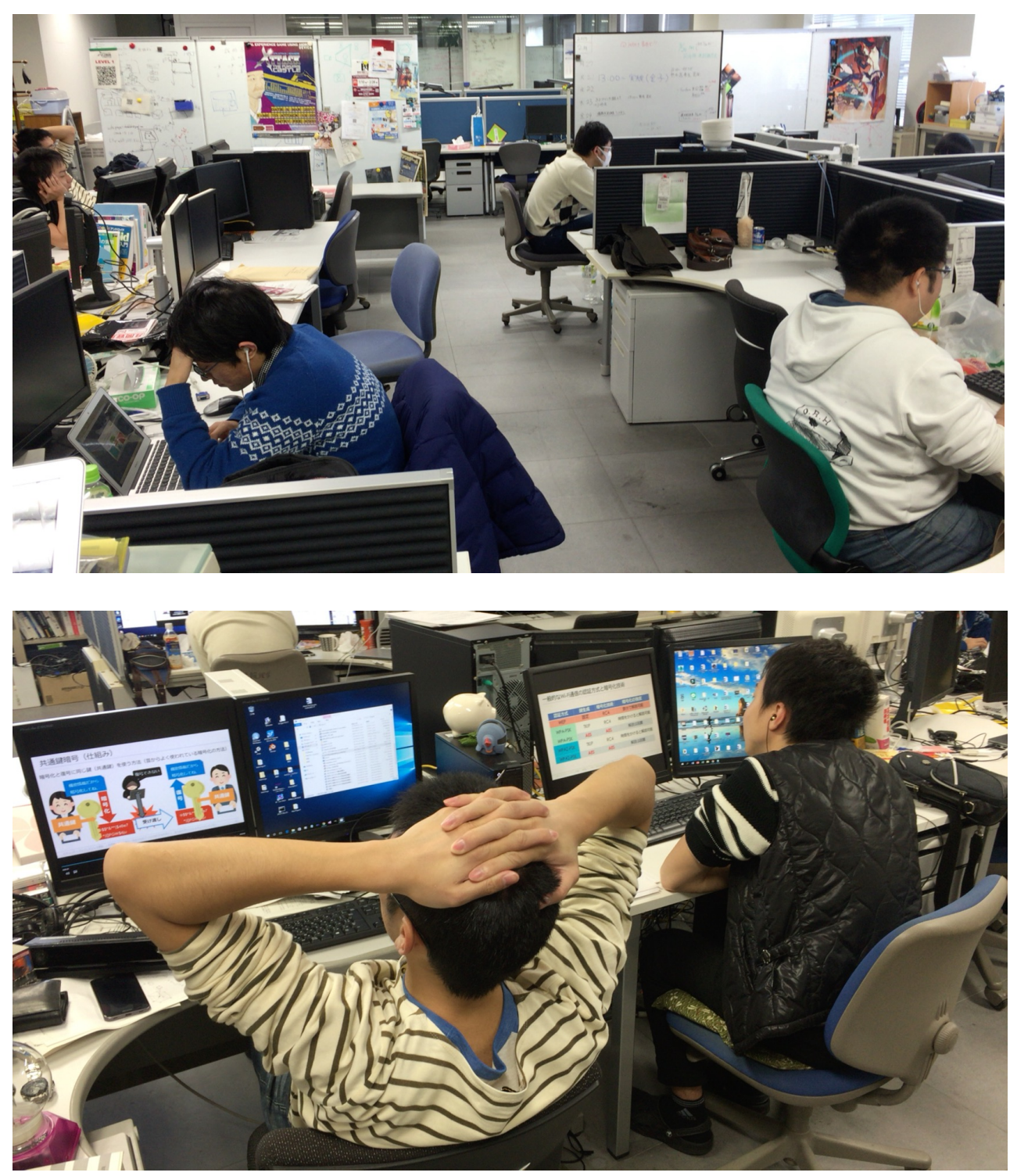

Figure 6: Appearances of non-experiential learning course. 


\subsection{Procedure of comparative experiment}

Figure 7 shows the procedures of the two learning courses. As described in the upper diagram in Figure 7, experiential learning has four stages in one lesson unit. In the first stage, learner took a pre-test which was a kind of metrics that how much knowledge a learner already had before the lesson. The pre-test has five questions and each question had five options (only one option was correct) in each lesson. The examination time of the pre-test was within $10 \mathrm{~min}$. The second stage is classroom lecture. We taught the knowledge of cyber-attacks and cyber-defenses about each security topic. The classroom lecture took about $30 \mathrm{~min}$. The third stage is exercise. Learner practically implemented security protections to the educational materials we prepared. The exercise took about $40 \mathrm{~min}$. Lastly, every learner took post-test which was a kind of metrics that how much knowledge a learner can acquire through this classroom lecture and practical exercise. The content of the post-test was the same one of the pre-test. The examination time of the post-test was within $10 \mathrm{~min}$. The lesson unit was repeated seven times according to the seven topics as No. $3,4,5,6,8,9$ and 10 of the curriculum listed in Table 1. Each lesson was held by one week. The delayed-test was held about one month later after finishing the seventh times lecture. The test score was the main metrics in this research that how much knowledge a learner can keep retaining even one month later. The contents of the delayed-test were picked up in the post-tests of thirtyfive questions. Twenty questions were selected as the contents of the delayed-test.
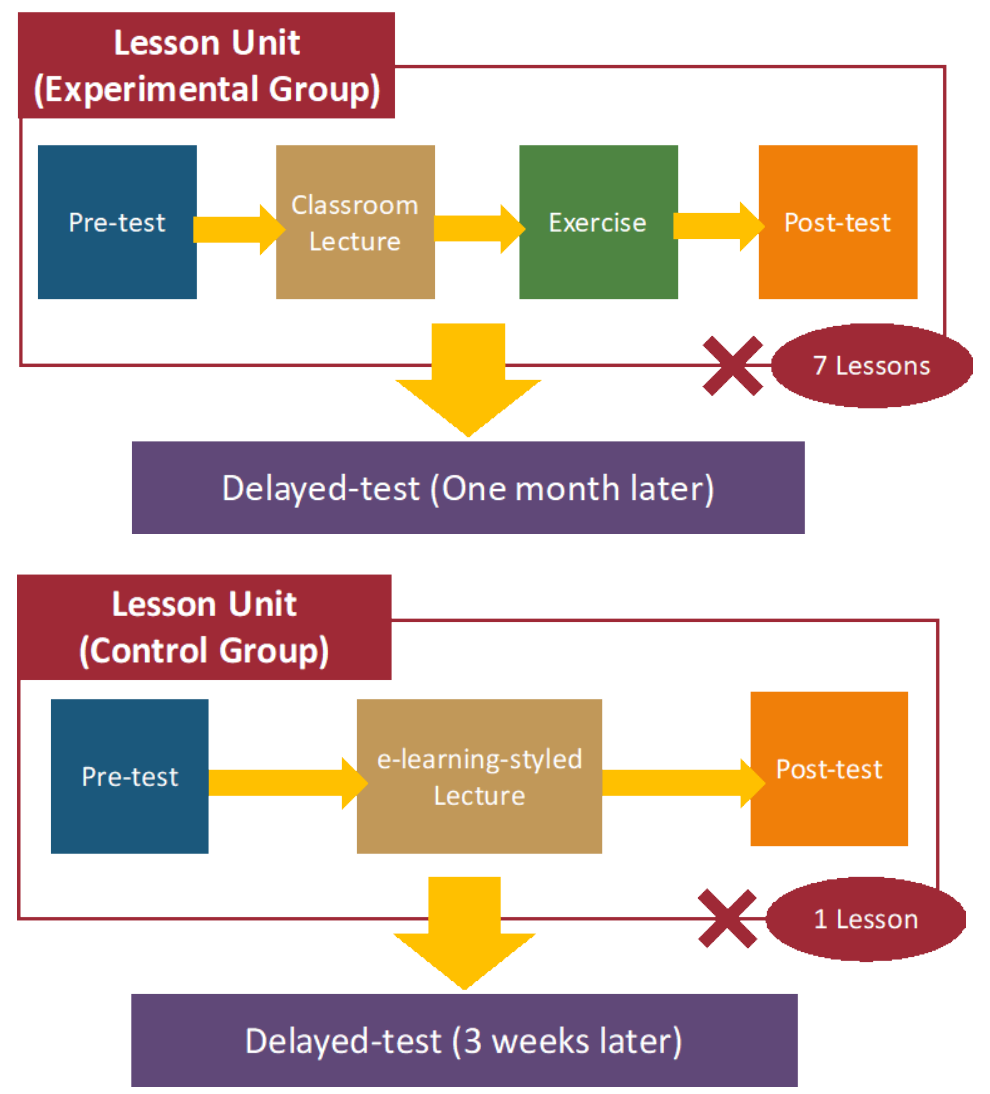

Figure 7: Overview of the process of each experiment. 
As showing in the lower diagram in Figure 7, the lesson unit of non-experiential learning took three stages as well as the experiential learning except from practical exercises. The pre-test had the same contents of thirty-five questions. Because a learner needed to answer the questions all at once, the pre-test took from about $30 \mathrm{~min}$. to one hour. The second stage was e-learning. Learner watched a video explaining the same contents of the classroom lecture in the experiential learning. As we explained before, the play time of the video content were about $30 \mathrm{~min}$. Lastly, learner took the post-test which was the same contents of the pre-test. Different from the experiential learning case, the lesson unit was executed only one time. About three weeks later, the learners took the delayed-test which was also the same content of the delayed-test examined in the experiential learning.

\subsection{Situation of comparative experiment}

Table 3 shows status of learners who took the experiential learning course. Twelve learners participated in the course. Ten learners were undergraduate students in our university and the others were policemen who came from a local police station for learning knowledge about cybersecurity. All learner didn't have knowledge about cybersecurity so much before they took the learning course. Table 4 shows status of learners who took the non-experiential learning course. Eight learners participated in the course. Seven learners were graduate students in our university and their major was computer science. The other was undergraduate student who was major in physics in faculty of science.

Table 3: Learners' status in experiential learning course

\begin{tabular}{|c|c|r|r|}
\hline Type & Faculty & School Year & Total \\
\hline Undergraduate Students & Engineering & 1 & 5 \\
\hline Undergraduate Students & Engineering & 2 & 1 \\
\hline Undergraduate Students & Science & 1 & 3 \\
\hline Undergraduate Students & Science & 3 & 1 \\
\hline Policemen & - & - & 2 \\
\hline
\end{tabular}

Table 4: Learners' status in non-experiential learning course

\begin{tabular}{|c|c|r|r|}
\hline Type & Faculty & School Year & Total \\
\hline Graduate Students & Computer Science & 2 & 6 \\
\hline Graduate Students & Computer Science & 1 & 1 \\
\hline $\begin{array}{c}\text { Undergraduate Stu- } \\
\text { dents }\end{array}$ & Science & 1 & 1 \\
\hline
\end{tabular}




\section{Experimental Results}

This research purpose was to investigate learning effectiveness of experiential learning group and non-experiential learning group. The evaluation metrics were pre-/post-test scores, delayed-test score and learning motivation score. Figure 8 shows the average of pre-test score and post-test score. Each leaner is aligned the horizontal line and the vertical line means test score. Because the bar graph shows an average score of pre-tests and post-tests containing five questions in each lesson, the range of value becomes from 0 to 5 . The blue and orange bars mean average of the pre-test score and the post-test score, relatively. The twelve learners for the left side are who took the experiential learning and the others are who took the non-experiential learning. Every orange bar is higher than blue one, which means that each learner acquired knowledge and skill about cybersecurity than before they attended to each lesson. Figure 9 shows the delayed-test scores of each learner. As well as the pre-/post-test score, learners are aligned in the horizontal line and the vertical line means test score. Because the delayed-test had twenty questions, the range of value is from 0 to 20 . We use a modified IMMS based on our previous research [6]. The students were required to rate all items with 5-likert scale (1: don't agree at all - 5: agree very much). Table 8 showed in Appendix displays the items of the modified IMMS for this research. Figure 10 is average scores of ARCS elements appearing in IMMS. Each leaner is aligned the horizontal line and the vertical line means test score. The blue, orange, gray and yellow bars mean average scores of ARCS element of Attention, Relevance, Confidence and Satisfaction, relatively. Table 5. describes actual values of the average of the pre-test score, the post-test score and the delayed test between the two groups. Table 6 shows the analytical results of Wilcoxon Rank Sum Test about Test Scores of Each Group. The meaning of "Rising Value" is the difference of average score between the pre-test score and post-test score of each lesson. The metrics means that how much scores were improved between the situation before lesson and after lesson. The result of the rank sum test mentions that there was no significant difference of the Rising Value between the two group. However, the result of the rank sum test shows that there was significant difference of the delayed-test score between the two groups. Table 7 shows the analytical results of Wilcoxon Rank Sum Test about IMMS Scores of Each Group. The result of the rank sum test mentions that there was no significant difference of each ARCS element of IMMS score between the two group. 


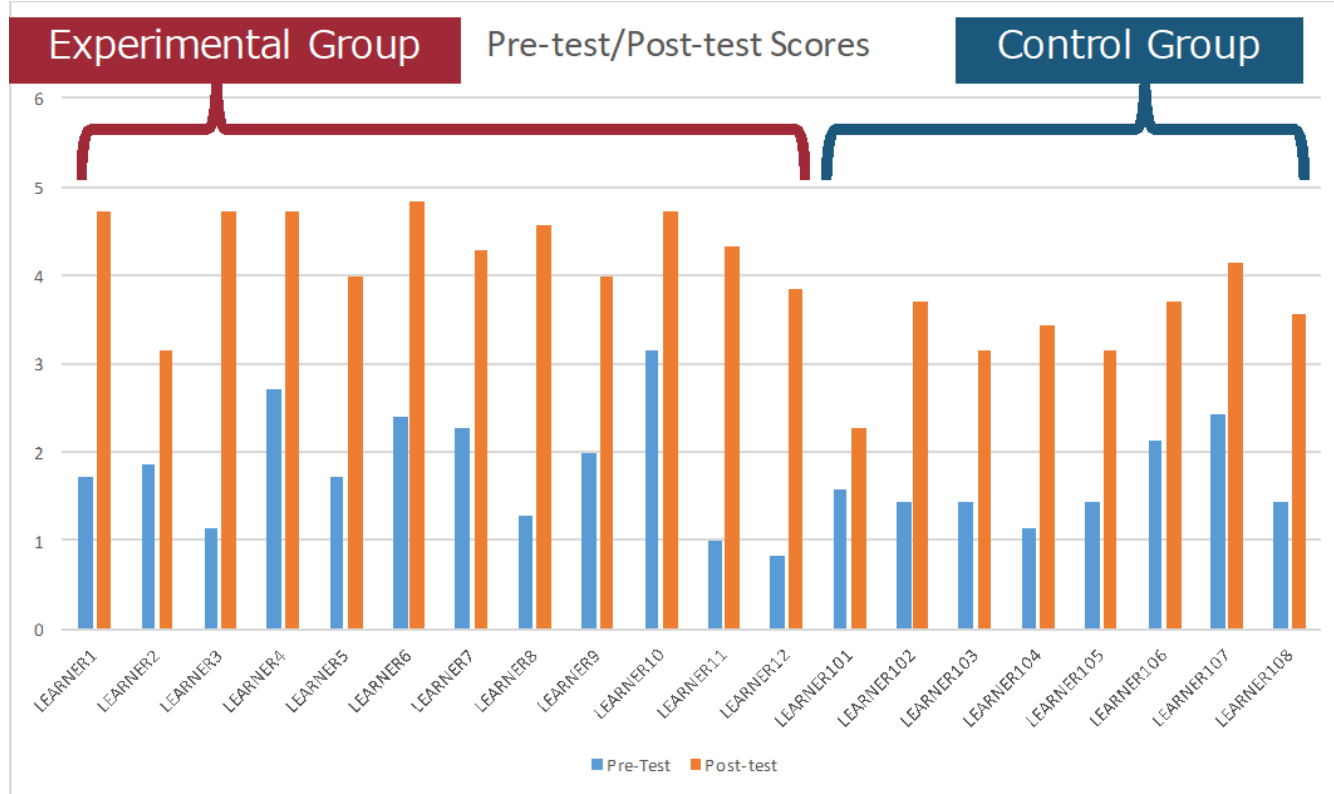

Figure 8: Average scores of pre-test and post-test of each learner

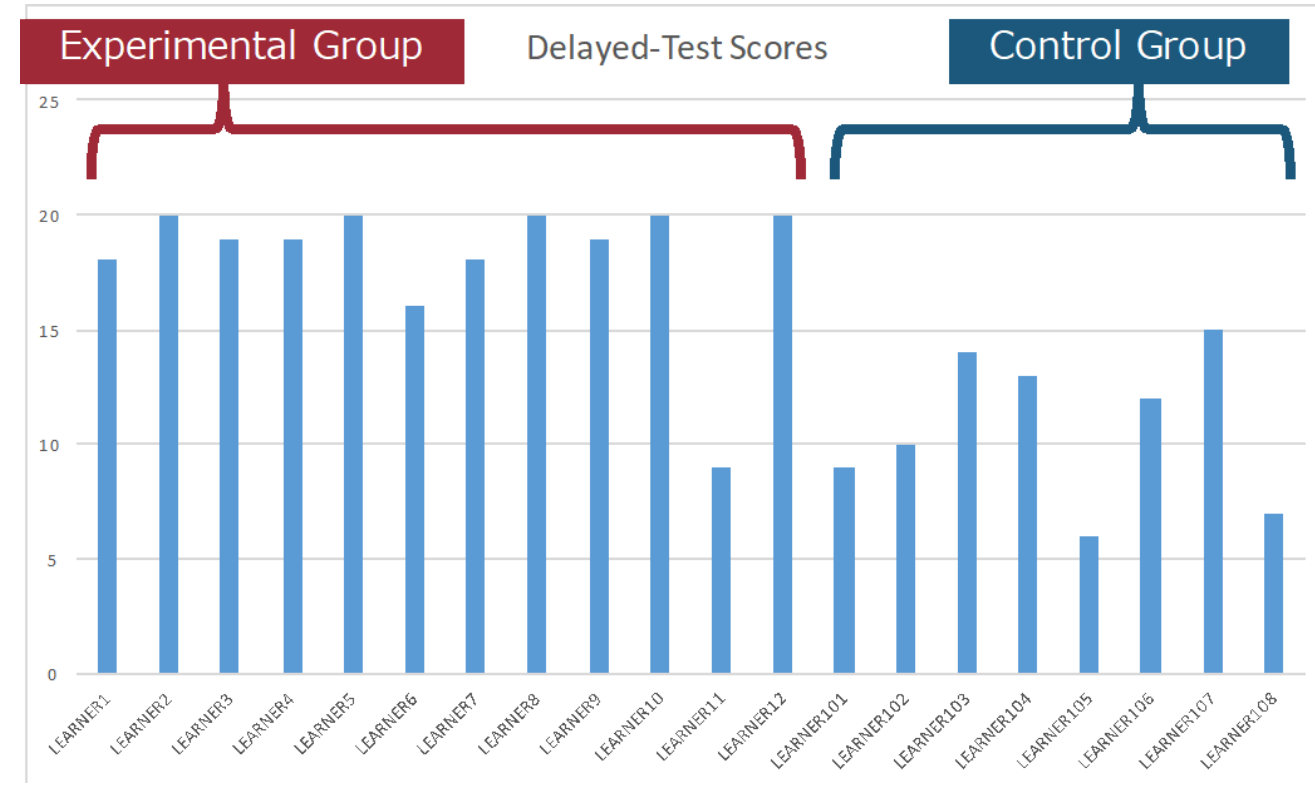

Figure 9: Delayed-test scores of each learner 


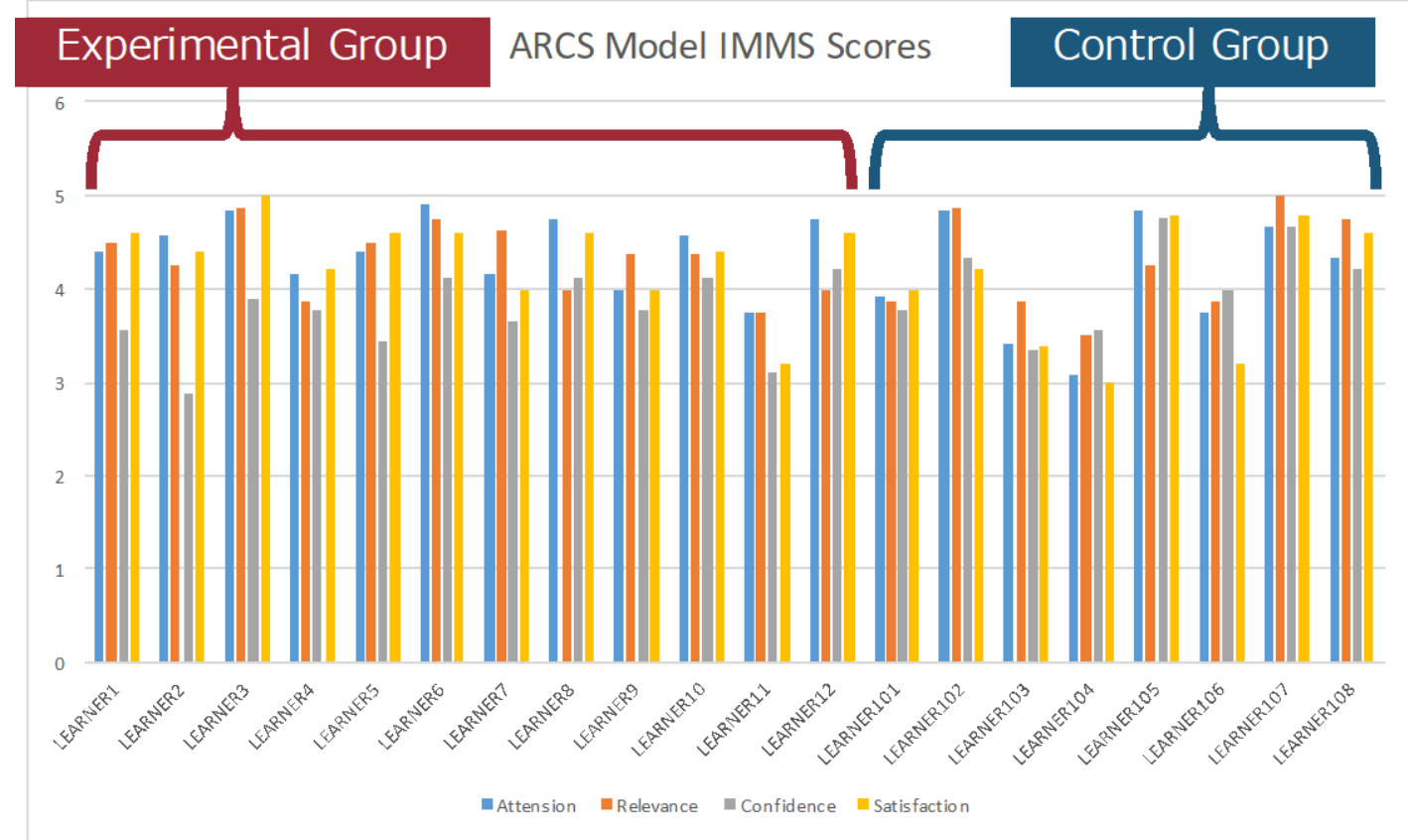

Figure 10: Average scores of ARCS elements appearing in IMMS

Table 5: Results of average test score of each group

\begin{tabular}{|c|c|c|}
\hline & Experimental Group & Control Group \\
\hline Pre-test (Min:0 - Max:5) & 1.84 & 1.63 \\
\hline Post-test (Min:0 - Max:5) & 4.32 & 3.39 \\
\hline Delayed-test (Min:0 - Max:20) & 18.17 & 10.75 \\
\hline
\end{tabular}

Table 6: Result of Wilcoxon Rank Sum Test for pre-/post-test scores and delayed-test score

\begin{tabular}{|c|c|c|c|c|c|}
\hline \multirow{2}{*}{} & \multicolumn{2}{|c|}{ Mean } & \multicolumn{2}{c|}{ Median } & \multirow{2}{*}{$\mathrm{Z}$} \\
\cline { 2 - 5 } & Exp. & Cnt. & Exp. & Cnt. & \\
\hline Rising Value & 2.48 & 1.77 & 2.36 & 1.71 & $1.90^{\mathrm{a}}$ \\
\hline Delayed-test & 18.17 & 10.75 & 19 & 11 & $3.31^{\mathrm{b}}$ \\
\hline
\end{tabular}

${ }^{a} \mathrm{p}>0.05, \quad{ }^{b} \mathrm{p}<0.01$ 
Table 7: Result of Wilcoxon Rank Sum Test for IMMS

\begin{tabular}{|c|c|c|c|c|c|}
\hline & \multicolumn{2}{|c|}{ Mean } & \multicolumn{2}{c|}{ Median } & \multirow{2}{*}{$\mathrm{Z}$} \\
\cline { 2 - 5 } & Exp. & Cnt. & Exp. & Cnt. & \\
\hline Attention & 4.44 & 4.10 & 4.50 & 4.13 & $1.05^{\mathrm{a}}$ \\
\hline Relevance & 4.32 & 4.25 & 4.38 & 4.06 & $0.39^{\mathrm{a}}$ \\
\hline Confidence & 3.72 & 4.08 & 3.78 & 4.11 & $1.47^{\mathrm{a}}$ \\
\hline Satisfaction & 4.35 & 4.00 & 4.50 & 4.10 & $0.82^{\mathrm{a}}$ \\
\hline
\end{tabular}

${ }^{\mathrm{a}} \mathrm{p}>0.05$

\section{Discussion}

In this section, we would like to discuss about the experimental result. As we mentioned before, the score of "Rising Value" was no significant difference between the two groups. Also, there was no significant difference about the score of learning motivation between the two groups. On the other hand, the delayed-test score was significant difference between the two groups. The result shows that learners in both groups had motivation for their course and they could acquire knowledge than before they attended to their course. However, the different influence to knowledge retention rate was occurred in each group. Almost learners in the experiential learning course could keep retaining knowledge they learned meanwhile almost earners in the non-experimental learning course couldn't. The result indicates one of the reasons why they could keep their knowledge; namely because they had "experience". There is another evidence to support this fact. The LEARNER11 in Figure 8 had good scores in post-test. He surely acquired knowledge just when he completed each lesson. However, his delayed-test score described in the Figure 9 was remarkably lower than the others in the experimental group. Only he couldn't retain his knowledge even in the experimental group. One of the reasons is related with his attendance rate to the exercises. He absented four times in the seven lessons. In other words, he didn't experience the exercises so much and consequently his situation was similar to the situation of the control group. Therefore, he couldn't keep his knowledge different from the other members in the experimental group. The result shows one of evidences to statistically prove that an experiential learning influences to knowledge retention on cybersecurity education. 


\section{Conclusion and future works}

This paper showed the result of comparative experiment of experiential learning and non-experiential learning on cybersecurity education. Learners in both groups had learning motivation and acquired knowledge in their lesson, however, there was significant difference about knowledge retention rate between the two group. The result indicated that "experience" influenced to knowledge retention rate of learners. Also, the result showed one of statistical evidences that experiential learning has possibility to bring long-term knowledge retention than the case of nonexperiential learning. In conclusion, we need to design instruction including experiential exercises in order to practice effective cybersecurity education. As future works, we also plan to collect objective data such as learner's log data during operating educational materials in order to investigate relevance between learner's behavior and learning effectiveness.

\section{Acknowledgement}

We deeply grateful to cybersecurity engineers of Fujitsu Limited. They have kindly supported to build the curriculum and instructional design of this IoT security engineering course with us.

\section{References}

[1] Ministry of Economy, Trade and Industry in Japan, 2014, http://www.meti.go.jp/policy/it_policy/jinzai/27FY/ITjinzai_report_summary.pdf

[2] White paper 2016, information and communication in Japan, Ministry of Internal Affairs and Communications in Japan, 2016,

http://www.soumu.go.jp/johotsusintokei/whitepaper/eng/WP2016/2016-index.html

[3] Security Engineering in Kyushu University Syllabus

URL : https://ku-portal.kyushuu.ac.jp/campusweb/slbssbdr.do?value\%28risyunen\% 29=2016\&value $\% 28$ semekikn $\% 29=1 \&$ value $\% 28$ kougicd $\% 29=16533826 \&$ value $\%$ 28 crclumcd $\% 29=\mathrm{ZZ}$

[4] National Training Laboratories

[5] J. M. Keller, Motivational Design for Learning and Performance: The ARCS Model Approach, Springer Science and Business Media, 2009.

[6] K. Kaneko, Y. Saito, Y. Nohara, E. Kudo, M. Yamada, A Game-Based Learning Environment Using the ARCS Model at a University Library, IIAI 4th International Congress on Advanced Applied Informatics, IEEE, pp.403-408, 2015. 


\section{Appendix}

Table 8: Modified IMMS items (Keller, 2009) for this research

\begin{tabular}{|c|c|c|}
\hline \# & ARCS & Item \\
\hline 1 & $\mathrm{C}$ & $\begin{array}{l}\text { When I first looked at this material, I had the impression that it would be easy } \\
\text { for me }\end{array}$ \\
\hline 2 & A & $\begin{array}{l}\text { There was something interesting at the beginning of the material hat got my } \\
\text { attention }\end{array}$ \\
\hline 3 & $\mathrm{C}$ & This material was more difficult to understand than I would like for it to be $(*)$ \\
\hline 4 & $\mathrm{C}$ & $\begin{array}{l}\text { After reading the introductory information, I felt confident that I knew what I } \\
\text { was supposed to learn from this material }\end{array}$ \\
\hline 5 & $\mathrm{~S}$ & $\begin{array}{l}\text { Completing the exercises in this lesson gave me a satisfying feeling of accom- } \\
\text { plishment }\end{array}$ \\
\hline 6 & $\mathrm{R}$ & $\begin{array}{l}\text { It is clear to me how the content of this material is related to things I already } \\
\text { know }\end{array}$ \\
\hline 7 & $\mathrm{C}$ & $\begin{array}{l}\text { Many of the pages had so much information that it was hard to pick out and } \\
\text { remember the important points }(*)\end{array}$ \\
\hline 8 & A & These materials are eye-catching \\
\hline 9 & $\mathrm{R}$ & $\begin{array}{l}\text { There were stories, pictures, or examples that showed me how this material } \\
\text { could be important to some people }\end{array}$ \\
\hline 10 & $\mathrm{R}$ & Completing this lesson successfully was important to me \\
\hline 11 & A & The quality of the writing helped to hold my attention \\
\hline 12 & A & This material is so abstract that it was hard to keep my attention on it $\left(^{*}\right)$ \\
\hline 13 & $\mathrm{C}$ & As I worked on this material, I was confident that I could learn the content \\
\hline 14 & $\mathrm{~S}$ & $\begin{array}{l}\text { I enjoyed this material so much that I would like to know more about this } \\
\text { topic }\end{array}$ \\
\hline 15 & A & The pages of this material look dry and unappealing $(*)$ \\
\hline 16 & $\mathrm{R}$ & The content of this material is relevant to my interests \\
\hline 17 & A & The way the information is arranged on the pages helped keep my attention \\
\hline 18 & $\mathrm{C}$ & The exercises (post-test) in this material were so difficult $(*)$ \\
\hline 19 & A & his material has things that stimulated my curiosity \\
\hline
\end{tabular}




\begin{tabular}{|c|c|c|}
\hline 20 & $\mathrm{~S}$ & I really enjoyed studying this material \\
\hline 21 & A & The amount of repetition in this material caused me to get bored sometimes $(*)$ \\
\hline 22 & $\mathrm{R}$ & $\begin{array}{l}\text { The content and style of writing in this material convey the impression that its } \\
\text { content is worth knowing }\end{array}$ \\
\hline 23 & A & I learned some things that were surprising or unexpected \\
\hline 24 & $\mathrm{C}$ & $\begin{array}{l}\text { After working on this material for a while, I was confident that I would be } \\
\text { able to pass a test on it }\end{array}$ \\
\hline 25 & $\mathrm{R}$ & $\begin{array}{l}\text { This material was not relevant to my needs because I already knew most of } \\
\text { it }(*)\end{array}$ \\
\hline 26 & A & $\begin{array}{l}\text { The variety of reading passages, exercises, illustrations, etc., helped keep my } \\
\text { attention on the lesson }\end{array}$ \\
\hline 27 & A & The style writing is boring $(*)$ \\
\hline 28 & $\mathrm{R}$ & $\begin{array}{l}\text { I could relate the content of this material to things I have seen, done, or } \\
\text { thought about in my own life }\end{array}$ \\
\hline 29 & A & There are so many words on each page that it is irritating $(*)$ \\
\hline 30 & $\mathrm{~S}$ & It felt good to successfully complete this lesson \\
\hline 31 & $\mathrm{R}$ & The content of this material will be useful to me \\
\hline 32 & $\mathrm{C}$ & I could not really understand quite a bit of the material $(*)$ \\
\hline 33 & $\mathrm{C}$ & $\begin{array}{l}\text { The good organization of the content helped me be confident that I would } \\
\text { learn this material }\end{array}$ \\
\hline 34 & $\mathrm{~S}$ & a pleasure to work on such a well-designed material \\
\hline
\end{tabular}

*: Reversed items 